\title{
La cantidad virtual (quantitas virtualis) según Tomás de Aquino
}

\section{Virtual quantity (quantitas virtualis) according to Thomas Aquinas}

\author{
Martín F. ECHAVARRÍA \\ (Universitat Abat Oliba CEU - Barcelona)
}

Recibido: 20/04/2012

Aceptado: 07/11/2012

\section{Resumen}

Tomás de Aquino distingue la cantidad como predicamento (quantitas dimensi$v a$ ) de la medida de perfección de una cosa, su cantidad virtual (quantitas virutalis or virtutis). El Aquinate diferencia la cantidad virtual de la esencia, del ser y de la operación. El concepto de cantidad virtual juega un rol central en la metafísica de la participación, pues participar es como tomar una "parte" de un todo, y tal parte representa un determinado monto de perfección. Por esta vía, la cantidad virtual se relaciona con la noción de virtus essendi. De la cantidad virtual derivan otros conceptos como los de igualdad virtual, contacto virtual, ubicación virtual, distancia virtual, etc., que reflejan la riqueza con que nuestro autor concibe el mundo cualitativo y espiritual.

Palabras clave: cantidad virtual; filosofía del ser; filosofía escolástica; metafísica; participación; Tomás de Aquino; virtus essendi.

\begin{abstract}
Thomas Aquinas distinguishes quantity as a predicament (quantitas dimensiva) from the mesure of the perfection of a being, which is called virtual quantity (quantitas virtualis or virtutis). Aquinas applies the concept of virtual quantity to the essence, being and operation. This is a central notion in Thomas Aquinas' metaphysics of participation, for participation is like taking a "part" of a hole and that part represents a certain amount of perfection. Hence virtual quantity relates to the concept of virtus essendi. From virtual quantity emanates other concepts: virtual
\end{abstract}


equality, virtual contact, virtual location, virtual distance, etc, that reflects the richness of Aquinas' coneption of qualitative and spiritual world.

Keywords: Methaphysics; Participation; Philosophy of Being; Thomas Aquinas; Scholastic Philosophy; Virtual Quantity; virtus essendi.

\section{Cantidad dimensional y cantidad virtual}

El concepto de cantidad virtual juega un papel central en la metafísica de Tomás de Aquino. A pesar de ello, raramente se lo encuentra desarrollado en las presentaciones sistemáticas de su pensamiento ${ }^{1}$.

La palabra cantidad designa generalmente en la obra del Aquinate a uno de los predicamentos enumerados por Aristóteles. Se trata de un accidente propio de las sustancias materiales y se divide en dos especies: cantidad continua o magnitud y cantidad discreta o multitud. La cantidad es un todo integral que es divisible en partes, continuas en el caso de la magnitud y discretas en el de la multitud, que surge justamente del fraccionamiento de una cantidad continua. Las partes de la cantidad no se interpenetran sino que están una fuera de la otra (partes extra partes). La magnitud da a la sustancia corpórea el carácter de extensa y posee tres dimensiones (latitud, longitud y profundidad). ${ }^{2}$ En la cantidad se apoyan los otros accidentes de las sustancias materiales, como sus cualidades, relaciones, la disposición de sus partes, su ubicación, etc.

Sin embargo, con mucha frecuencia, santo Tomás utiliza la palabra cantidad con otro sentido. Al hacerlo no habla de la cantidad simplemente sino con algún adjetivo añadido. Las más de las veces la expresión empleada es cantidad virtual (quantitas virtualis) o cantidad de virtud (quantitas virtutis). Además de estas expresiones, el Aquinate se sirve de otras que les son próximas, aunque no necesariamente sinónimas: magnitudo spiritualis ${ }^{3}$, quantitas intensiva ${ }^{4}$, quantitas perfectionis ${ }^{5}$, quantitas actus ${ }^{6}$, quantitas bonitatis ${ }^{7}$ y quantitas potentiae ${ }^{8}$. Santo Tomás diferencia

\footnotetext{
${ }^{1}$ La excepción más significativa es O'Rourke, F.: Pseudo-Dionysius and the Metaphysics of Aquinas, Notre Dame-Indiana, University of Notre Dame Press, 2005, pp. 156-167 y antes que él Ramírez, J. M.: Opera Omnia. Tomus II: De analogia, Madrid, CSIC., 1972, p. 1543ss.

2 Cfr. Aristóteles: Metafísica, $\Delta, 13$ (1020a, 7-14). Cfr. S. Tomás de Aquino In Metaph., lib. 5 1. 15 n.

2. A partir de aquí al citar las obras de santo Tomás no se pondrá el nombre del autor.

${ }^{3}$ Cfr. S. Th., I, q. 42, a.1, ad 1.

4 Cfr. De Ver., q. 2, a. 9, co

5 Cfr. In IV Sent., dist. 49, q. 2, a. 5, co.

${ }^{6}$ Cfr. In IV Sent., dist. 16, q. 3, a. 1B, ad 6; S. Th., I-II, q. 19, a. 8, co.

7 Cfr. In I Sent., dist. 44, q. 1, a. 1, ad 3.

8 Cfr. In IV Sent., dist. 49, q. 2, a. 5, co; In I Sent., dist. 44, q. 1, a. 4, ad 5 ; De Potentia, q. 1, a. 2, co.
} 
esta cantidad virtual del predicamento de la cantidad, al que designa como cantidad de mole (quantitas molis ${ }^{9}$ ), cantidad dimensional (quantitas dimensiva ${ }^{10}$ ), cantidad extensiva (quantitas extensiva11) o magnitud corporal (magnitudo corporalis ${ }^{12}$ ).

Cantidad dimensional y cantidad virtual 13 no son dos especies de un mismo género que se predique de modo unívoco. La cantidad virtual se coloca en el género de la cualidad o, más propiamente, en el orden de las formas (ya que, como veremos, se puede hablar de cantidad virtual no sólo en el orden accidental, o incluso predicamental en general, sino también al nivel de los "transcendentia"). Santo Tomás no aclara si se trata de una pura equivocidad (aunque dice que las sustancias espirituales pueden estar en un lugar por la cantidad virtual, pero equívocamente) o de analogía, que es a lo que nos inclinamos. El uso de la palabra similitudo en este contexto puede apuntar hacia la analogía de proporcionalidad más que hacia la predicación pros hen. La semejanza se establece especialmente con la magnitud, en la que se da lo grande y lo pequeño, aunque también hay multitud fuera del orden de la cantidad material, pues uno y múltiple "sunt de transcendentibus 14 ".

Algunos ejemplos de cantidad virtual son éstos: la grandeza en virtud (ej. la virtud de Héctor es grande), que puede dar lugar a una comparación de más y menos (ej. Juan es más virtuoso que Pedro); la mayor o menor capacidad cognoscitiva (sensitiva o intelectiva); la mayor o menor intensidad de un color (ej. esta rosa es más roja que esta otra); la mayor perfección de una naturaleza respecto de otra (ej. la perfección del hombre es más grande que la del caballo). En los tres primeros casos, nos encontramos con una grandeza de orden cualitativo; el último pertenece al género de la sustancia. Con esto se ve que la noción de cantidad virtual no se coloca meramente al nivel de la cualidad, sino más en general de la forma o acto y, por lo tanto, a nivel trascendental. La cantidad virtual hace referencia a una magnitud de perfección, o a una determinada medida según la cual se posee una perfección. Por esta vía, la noción de cantidad virtual se conecta con la de modo, en especial de modus essendi, así como con la de poder y virtud, y en particular con la de virtus essendi, y por ello con la doctrina metafísica de la participación, como se dirá.

Si la noción de cantidad como predicamento está tomada explícitamente de Aristóteles, santo Tomás no hace referencia a ninguna fuente al hablar de la canti-

\footnotetext{
${ }^{9}$ Cfr. S. Th. I, q.42, a.1, ad 1.

10 Por ejemplo, cfr, In II Sent., dist.3, q. 1, a. 4, co.; Contra Gentes, 1. 4, c. 63; S. Th. I, q.42, a.1, ad 1 ; etc.

11 Cfr. De Pot., q.1, a. 2, co.

12 Cfr. In III Physicorum, 1. 7; In III Metaphysicurum, 1. 12.

13 A estas dos, habría que añadir la cantidad matemática, si bien ésta se obtiene por abstracción formal a partir de la cantidad dimensiva y, por lo tanto, es reductible a ésta.

14 Cfr. S. Th., I, q. 50, a. 3, ad 1; De Spir. Creat., a. 8, ad 15; In III Phys., 1. 12, n. 5.
} 
dad virtual. ${ }^{15}$ Parece ser, por lo tanto, una doctrina propia. Sin embargo, detrás de ella se vislumbran los mismos influjos que están en la base de su doctrina de la participación: las fuentes platónicas, especialmente en su interpretación cristiana, en particular Dionisio el Areopagita y san Agustín. De este último, al tratar nuestro tema, cita con frecuencia esta frase: "in his enim quae non mole magna sunt hoc est maius esse quod est melius esse" 16 . El contexto de la frase es el de la explicación de la igualdad de las personas divinas, pero el tema ya había sido previamente tratado por el Hiponense en De quantitate animae. Santo Tomás, de hecho, se ocupa también de la cuestión de la cantidad virtual en el contexto del tratamiento de la igualdad de las personas en la Trinidad y de allí lo transporta a la solución de otros temas. En los cuerpos, se llama grande al que ha alcanzado toda la magnitud que le corresponde según su especie ${ }^{17}$. En el orden de las cualidades y las formas, en cambio, que por esencia no poseen magnitud extensiva, el más y el menos no hace referencia a la extensión sino que es intensivo. Se dice grande lo que es más perfecto. Por eso se puede decir que Dios es grande o aquello mayor que lo cual nada existe 18 .

En la Suma de Teología, a santo Tomás se le plantea la objeción de que no se puede hablar de igualdad entre las personas divinas, porque por igualdad se entiende tener la misma cantidad, pero Dios al no ser un cuerpo no puede decirse que tenga cantidad, ni por lo tanto igualdad 19 . Respondiendo a esta objeción, santo Tomás distingue la cantidad dimensional de la cantidad virtual:

La cantidad es de dos tipos. Una que se llama cantidad de mole, o cantidad dimensional, que sólo está en las cosas corporales, por lo que no se encuentra en las Personas divinas. Pero hay otra que es la cantidad de virtud, que se considera según la perfección de alguna naturaleza o forma, la cual cantidad se designa según que se dice que algo es más o menos cálido, en cuanto es más perfecto o menos perfecto en calidez. Este modo de cantidad virtual se considera primeramente en raíz, es decir, en la perfección misma de la forma o naturaleza, y así se llama magnitud espiritual, como se llama grande al calor por su intensidad y perfección. Y por eso Agustín dice, en el 1. VI Sobre la Trinidad, que "en las cosas que no son grandes por su mole, ser mayor es lo mismo que ser mejor", pues se llama mejor a lo que es más perfecto. En segundo lugar se considera la cantidad virtual en los efectos de la forma. El primer efecto de la forma es el ser, pues toda cosa tiene el ser según su forma. El segundo efecto es la operación, porque todo agente actúa por su forma. Por lo tanto, se considera la cantidad virtual, tanto según el ser, como según la operación. Según el ser, en cuanto las cosas que tienen una natu-

\footnotetext{
15 O'Rourke, Pseudo-Dionysius..., p. 164: "In none of the passages where he outlines the distinction between virtual and dimensive quantity does Aquinas attribute the doctrine to a particular source". 16 S. Agustín, De Trinitate, L. VI, c. 8.

17 S. Th., I-II, q. 52, a. 1.

18 Cfr. S. Th., III, q. 1, a. 1, ad. 4; Super Ps. 33, n. 4 ; Super Ps. 47, n. 1; In De Div. Nom., c. 9, 1.1.

19 S. Th., I, q.42, a.1, obj. 1.
} 
raleza más perfecta, tienen también mayor duración. Y según la operación, en cuanto las cosas que tienen una naturaleza más perfecta, son más potentes para actuar.

Por lo tanto, como dice Agustín en el libro Sobre la fe para Pedro, la igualdad se entiende en el Padre y el Hijo y el Espíritu Santo, en cuanto ninguno de ellos precede en eternidad, o excede en magnitud, o supera en potestad. 20

Este es uno de los pasajes fundamentales en que santo Tomás presenta la cantidad virtual y en él está contenido en síntesis casi todo lo que hay que decir sobre este tema. Hay dos tipos de cantidad: una cantidad dimensional y una cantidad virtual. En la objeción se divide la cantidad dimensional o de mole en cantidad continua intrínseca (magnitud), cantidad continua extrínseca (lugar y tiempo que miden extrínsecamente al cuerpo extenso) y la cantidad discreta (multitud o pluralidad). La cantidad virtual es, en cambio, algo así como una magnitud espiritual que consiste en la medida de intensidad de la perfección de una cosa, como por ejemplo el calor, que es una cualidad. Dicho esto, el Aquinate afirma que esta intensidad perfectiva de una forma se puede considerar en tres situaciones. En primer lugar, radicalmente, se puede hablar de la cantidad virtual de la forma misma. En segundo lugar, de aquello que se sigue de la forma: Primero, del ser; después, del operar. No es éste el momento de entrar en la dilucidación de en qué sentido el ser se dice efecto de la forma, discusión de gran actualidad en el tomismo contemporáneo. ${ }^{21}$ En todo caso, al tratar del ser como efecto de la forma en este preciso pasaje, santo Tomás piensa en la duración: las cosas más perfectas son de mayor duración. En lo que se refiere a la operación, la mayor perfección de una forma o naturaleza es la que a su vez fundamenta su poder operativo: a mayor perfección, mayor virtud. ${ }^{22}$ Esta triple distinción le permite señalar una casi tridimensionalidad de la cantidad virtual: intensidad perfectiva, duración y virtud, a semejanza de las tres dimensiones de la cantidad de mole, o tal vez mejor de las tres especies de cantidad enunciadas en la obje-

20 S. Th., I, q.42, a.1, ad 1.

21 Dejando de lado temas polémicos dentro de la escuela tomista, se puede decir que la forma da el ser o que de ella resulta o es consiguiente el ser, a modo de disposición última para la recepción del ser, de modo semejante a cómo lo diáfano es una disposición del aire para participar de la luz del sol. Y se dice sobre todo de los entes compuestos de materia y forma. Pero mirando "hacia arriba", la forma es receptora del ser y éste es el acto último de la sustancia y aquello por lo que ella más propiamente es., cfr. Contra Gentes, 1. II, c. 54: "Per hoc enim in compositis ex materia et forma dicitur forma esse principium essendi, quia est complementum substantiae, cuius actus est ipsum esse: sicut diaphanum est aeri principium lucendi quia facit eum proprium subiectum luminis. [...] In substantiis autem intellectualibus, quae non sunt ex materia et forma compositae, ut ostensum est, sed in eis ipsa forma est substantia subsistens, forma est quod est, ipsum autem esse est actus et quo est”; cfr. también $S$. Th., I, q. 104, a. 1, ad 1: "esse per se consequitur formam creaturae, supposito tamen influxu Dei, sicut lumen sequitur diaphanum aeris, supposito influxu solis".

22 Cfr. De Pot., q. 1, a. 2, co: "cum potentia activa sequatur actum, quantitas potentiae sequitur quantitatem actus; unumquodque enim tantum abundat in virtute agendi quantum est in actu." 
ción. Por ello, en la Trinidad se puede hablar de una igualdad en la duración de su ser, en la perfección esencial y en la virtud, pues "ninguno de ellos precede en eternidad, o excede en magnitud, o supera en potestad".

\section{La ratio participationis y la cantidad virtual}

El tomismo del siglo Xx, especialmente a partir de los estudios de Fabro23, redescubrió la centralidad de la noción de participación en la metafísica de santo Tomás. Éste toma esta noción de sus diversas fuentes imbuidas de platonismo: Boecio, Dionisio, el Liber De Causis, Avicena. ${ }^{24}$ El Aquinate dice en un par de textos que participar es "partem capere" (tomar una parte). ${ }^{25}$ Esta manera de expresarse tiene su origen en una semejanza con las cosas materiales, es decir, afectadas por la cantidad dimensional. Tal como hemos dicho, la cantidad predicamental se caracteriza por su divisibilidad en partes. En este sentido, tomar una parte implica no sólo dividir mentalmente el todo cuantitativo, sino deshacerlo. La participación de las realidades "cuantas" implica la partición y destrucción de lo participado, que no es común per se, pues lo participado no subsiste después de la participación, ya que el resultado es una cantidad discreta, cada una de cuyas unidades es reducida en su magnitud respecto del todo inicial26. Esto depende de la potencialidad de la materia, que de por sí no es comunicable. La noción de participación en santo Tomás no se refiere a esta repartición de la cantidad dimensional, sino a la participación de una forma, acto, perfección, que es lo propiamente comunicable, pero la noción tiene su origen de su semejanza con la partición de las realidades materiales. Esto es significativo en el tema que nos ocupa pues la cantidad virtual es llamada cantidad per similitudinem y, de la misma manera, la noción de participación está tomada por semejanza de la repartición de un todo dimensional. De aquí el parentesco que señalaremos entre la noción de participación y la de cantidad virtual. La participación en las formas y actos no parte ni destruye lo participado, ni reduce su cantidad virtual, sino que la deja intacta, lo cual a su vez deriva del carácter esencialmente perfecto y perfectivo de las formas. Las formas son por sí mismas comunicables. Esto distingue claramente la participación perfectiva, de la mera repartición material.

También la participación de una forma o acto es "quasi partem capere", pero esa "parte" que se toma no es dimensional sino virtual, y no es extensiva, sino inten-

\footnotetext{
${ }^{23}$ Cfr. los ya citados Fabro, C.: La nozione metafisica di partecipazione, Segni, EDIVI 2005 y FABRo, C.: Participación y causalidad según Tomás de Aquino, Pamplona, EUNSA, 2008; Geiger, L. B.: La participation dans la philosophie de saint Thomas d'Aquin, Paris, Bibliothèque Thomiste, 1942.

24 Fabro, La nozione metafisica..., pp. 43-120.

25 Cfr. In Boeth. De Hebd., lectio II; Super ad Hebr., c. 6, 1. 1: "Est autem participare, partem capere". 26 Cfr. Cardona, C.: La metafisica del bien común, Madrid, Rialp, 1966, p. 19.
} 
siva. Participar, en este sentido, es recibir limitada y particularmente, una perfección que a otro pertenece ilimitada o universalmente. Así lo expresa santo Tomás en un pasaje capital del comentario al De Hebdomadibus, de Boecio 27 :

Participar es como tomar una parte; y por eso, cuando algo recibe particularmente lo que a otro le pertenece universalmente, se dice que participa de aquello. Como se dice que hombre participa de animal, porque no tiene la razón de animal según toda su comunidad. Y por la misma razón Sócrates participa de hombre. Y de modo semejante también el sujeto participa del accidente y la materia de la forma, porque la forma sustancial o accidental, que por su noción es común, se determina a este o a aquel sujeto. Y también se dice que el efecto participa en su causa, y sobre todo cuando no iguala la virtud de su causa. Como si dijéramos que el aire participa de la luz del sol, porque no la recibe con esa claridad con que está en el sol.28

Lo que aquí describe como recibir particularmente lo que a otro pertenece universalmente, en otros lugares lo explica como tener por participación lo que otro es por esencia:

Pues lo que es algo totalmente, no participa de eso, sino que es por esencia eso mismo. Pero lo que no es totalmente algo, teniendo algo más añadido, se dice propiamente que participa.

Como si el calor fuera un calor existente por sí, no se diría que participa del calor, porque en él no habría nada más que calor. Pero el fuego, dado que es otra cosa que calor, se dice que participa del calor. ${ }^{29}$

Aquí se dice algo muy importante para comprender la doctrina tomista de la participación: La participación implica una composición. En el comentario al De Hebdomadibus, santo Tomás demuestra primeramente la composición desde el punto de vista lógico y en segundo lugar la composición real, especialmente la composición entre ente y esse. La composición se da entre un sujeto, que se dice participar de una forma o perfección, y tal forma o perfección. Por eso, participante y participado son distintos y se relacionan entre sí como la potencia y el acto. De esta manera, santo Tomás integra la concepción aristotélica sobre la composición acto-

\footnotetext{
27 Cfr. Fabro: La nozione metafisica ..., p. 30: "Il punto di partenza obligatorio per ogni indagine intorno alla nozione tomista di partecipazione è il Commento giovanile, come pare, dell'Angelico Maestro al De Hebdomadibus di Boezio"; p. 31: "S. Tommaso nel Commento al testo di Boezio ci ha dato, tutta di getto, l'esposizione della nozione metafisica di partecipazione, e fra i testi tomisti ch'io conosco questo resta il più completo e sistematico. Le implicazioni dottrinali seguono l'una all'altra in modo serrato, senz'alcun riferimento d'ordine storico, onde è il pensiero personale dell'Aquinate che qui viene espresso."

28 In Boeth. De Hebd., 1. 2.

29 In Metaph., L. I, 1. 10, n. 4.
} 
potencial, con la concepción platónica de la participación. ${ }^{30}$ Siendo distintos entre sí, lo que participa no se identifica con lo participado y, por lo tanto, teniéndolo en modo disminuido, participa de otras perfecciones o formas diversas. En cambio, lo que es esa forma imparticipadamente, es esa perfección absoluta e ilimitadamente, sin nada añadido ni limitante de su plena expansión como lo que ella es. ${ }^{31}$

El ejemplo que pone santo Tomás sobre el calor subsistente por sí (una quimera que sirve simplemente para ejemplificar, pero que no deja de tener su fuerza) y el calor participado, nos va conduciendo ya a la conexión entre participación y cantidad virtual. Lo que participa de una perfección no la tiene según todo su poder, sino con medida, limitadamente. Sólo lo que es tal perfección por esencia la tiene según toda su virtud. Santo Tomás pone con frecuencia el ejemplo de la blancura y lo blanco que participa de la blancura. Sólo lo blanco subsistente (si realmente se diera) tendría el blanco según todo el poder del blanco: "Toda forma recibida en algo, es limitada y delimitada según la capacidad del recipiente, por lo que este cuerpo blanco no tiene toda la blancura según todo el poder de la blancura". $32 \mathrm{La}$ perfección que en aquello que se identifica con ella por esencia se posee según todo su poder, en lo que participa de tal perfección se da limitada a la capacidad de quien recibe y, por tanto, en modo finito. Las diferentes medidas en que las distintas cosas participan en una perfección dan lugar a una mayor o menor "cantidad" de esa perfección; precisamente, una cantidad "de virtud". Justamente de la virtud de ser eso de lo que se participa. Así como la noción de actus essendi juega un rol central en la metafísica tomista, en el tema que nos ocupa es también capital la noción de virtus essendi.

\section{Quantitas virtualis y virtus essendi}

En el mismo lugar del comentario al De Hebdomadibus, santo Tomás fundamenta tanto la distinción nocional como la distinción real entre ente y ser recurriendo a la doctrina de la participación. Wippel, distingue tres sentidos en los cuales se habla de participación respecto del ser en las obras de santo Tomás:

\footnotetext{
30 Cfr. Elders, L.: Conversaciones filosóficas con santo Tomás de Aquino, San Rafael, Ediciones del Verbo Encarnado, 2009, p. 27: "Lo que participa de una perfección está relacionado con ella como la potencia al acto. Esto significa que, incluso con relación a la doctrina de la participación, Aristóteles tiene la última palabra: uno de los elementos centrales de la filosofía platónica es reducido a la doctrina del acto y de la potencia".

31 Evidentemente, mientras que los géneros y especies, así como las formas inherentes en la materia, no existen separadamente, hay perfecciones que pueden darse en su pureza separadamente de ella. Por este motivo, Fabro distingue entre una participación "predicamental" y una participación "trascendental". Cfr. Fabro, La nozione metafisica..., pp. 123- 258, especialmente, 174 y 175.

32 In De Div. Nom., cap. 5, lectio 1.
} 
a. Se dice en algunos lugares que los entes particulares participan en el ser común (esse commune).

b. Se dice en otros que el ente creado participa del Ipsum Esse subsistens, que es Dios.

c. Finalmente, en otras ocasiones se habla del ente en cuanto tiene participado el ser que es su perfección primera y complemento de actualidad. ${ }^{33}$

Los entes particulares participan en el esse commune, porque cada uno de ellos realiza "parte" de la perfección contenida en el esse commune, sin agotar ninguno de ellos la totalidad de la perfección del ser común. El ser común se puede interpretar en un sentido lógico y en un sentido metafísico. En sentido lógico, es la noción analógica del ser en toda su comunidad y antes de su distinción nocional en distintos esse (como el esse sustancial y el esse accidental, el esse en potencia o en acto, etc.). Pero santo Tomás parece usar esta expresión en un sentido también metafísico. No se entiende, por supuesto, el esse commune (ni el ens commune) como una especie de ser subsistente común a todos los entes particulares, como si estos fueran determinaciones accidentales de una realidad sustancial común. ${ }^{34}$ Pero sí el esse commune, en cuanto primer efecto del acto creador de Dios y en cuanto perfección que procede en común de su poder realizador designa justamente la totalidad del ser presente en la Creación. ${ }^{35}$ Esta totalidad del ser representa más perfectamente la eminentísima virtus essendi de Dios que el ser de cada una de las creaturas separadamente, si bien ni el esse de los entes particulares, ni el esse commune contienen la totalidad de la perfección divina. 36 De allí que en santo Tomás, tan central como la noción de actus essendi y de participación, sea la noción de orden: la totalidad de los entes creados forman entre sí una comunidad y un orden que en cuanto ente común y ser común imita en su riqueza la infinita plenitud del Ser de Dios ${ }^{37}$.

En todo caso, esta participación en el esse commune (tanto lógica, como real), no se debe desconectar de esa otra participación, la de cada ente y de la totalidad de la Creación que reciben limitadamente algo que en el Ipsum Esse subsistens se encuentra ilimitadamente. Dios no es el esse commune, sino que éste y el actus essendi de cada una de las creaturas son una participación de algo que en Dios se encuentra plenamente y sin medida. ${ }^{38}$ Dios es el Ser según toda la virtud del ser.

\footnotetext{
33 Wippel, J. F.: The Metaphysical Thought of Thomas Aquinas. From Finite Being to Uncreted Being, Washington, D.C., The Catholic University of America Press, 2000, pp. 119-120.

34 Contra Gentes, 1. 1, c. 26, n. 5.

35 Este parece ser el modo en que santo Tomás se refiere al esse commune en el comentario al De Divinis Nominibus; cfr. In De Div. Nom., c. 5, lectio 2. Cfr. O'Rourke: Pseudo-Dionysius..., pp. 148155; p. 148; Andereggen, I.E.M.: La Metafisica de santo Tomás en la Exposición sobre el De Divinis Nominibus de Dionisio Areopagita, Buenos Aires, EDUCA, 1989, p. 221.

36 Cfr. In De Div. Nom., c. 5, lectio 2.

37 Cfr. Cardona: Metafísica del bien común, pp. 30-31; Ramírez, J.M.: De ordine, Salamanca, San Esteban, 1963.

38 Cfr. In De Div. Nom., c. 5, lectio 2.
} 
Esto nos lleva a la noción de virtus essendi ${ }^{39}$, que está estrechamente conectada con la de quantitas virtualis.

[Dionisio] Muestra que todas [las perfecciones] corresponden a Dios, en cierto modo. Para evidenciar esto se debe considerar que toda forma recibida en algo es limitada y determinada según la capacidad del recipiente. Por lo cual, este cuerpo blanco no tiene toda la blancura según todo el poder de la blancura. Pero si existiera una blancura separada, nada le faltaría de lo que pertenece a la virtud de la blancura. Todas las demás cosas, como antes se ha dicho, tienen el ser recibido y participado, y por eso no tienen el ser según toda la virtud del ser. Sino que sólo Dios, que es el Ser subsistente mismo, tiene el ser según toda la virtud del ser. Y por eso dice [Dionisio] que por eso Dios puede ser la causa del ser para todas las cosas, porque Él no es existente en cierto modo, es decir, según algún modo finito y limitado, sino que Él universal e infinitamente contiene y precontiene en Sí todo el ser, porque en Él preexiste como en su causa y de Él deriva a las otras cosas. 40

Aquello que tiene una perfección participada no es esa perfección según todo su poder, sino que la posee limitadamente. Por el contrario, si esta perfección se da imparticipadamente, no sólo tiene, sino que es esa misma perfección según todo su poder o virtud. Todo ente creado tiene el ser participado, por lo que no es el ser según toda la virtud del ser, sino que posee parte del ser, es decir tiene esta perfección mesuradamente. Dios, en cambio, es el ser según toda la virtud del ser, por lo que en Él está contenida sin medida toda la perfección del ser41, no sólo del ser de cada cosa, ni del ser común, sino de un modo que trasciende infinitamente el ser de cada cosa y el ser común, pues la totalidad de la perfección del ser de Dios en toda su intensidad y sin límites es imparticipable y poseerla significa ser Dios mismo. Esto da lugar a hablar de una cantidad virtual de ser, justamente según la virtus essendi de cada cosa. ${ }^{42}$ La cantidad virtual es precisamente la cantidad de virtud, es decir la medida según la cual uno posee el poder de ser esa perfección. Hay por eso una cantidad de virtud de ser, que en las creaturas es limitada por estar recibida en una naturaleza finita, y que en Dios es ilimitada, por darse en plenitud. Por eso Dios es medida trascendente de la perfección de todas las cosas.

\footnotetext{
39 Sobre este tema, cfr. Gilson, E.: "Virtus essendi”, Mediaeval Studies, 26, 1964, pp. 1-11; O'Rourke, F.: "Virtus Essendi : Intensive Being in Pseudo-Dionysius and Aquinas", Dionysius, 15, 1991, pp. 3180; O'Rourke, F.: Pseudo-Dionysius..., pp. 155-187; Dewan, L.: "Aquinas on Virtus Essendi", The Thomist, 74 (2011), pp. 637-651. Sobre el tema de la virtus essendi como fundamento de una metafísica de la virtud, cfr. Echavarría, M. F.: "Virtud y ser según Tomás de Aquino", Espíritu, 138, 2009, pp. 9-36.

40 In De Div. Nom., c. 5, lectio 1.

41 Contra Gentes, 1.1, c. 28, n.2.

${ }^{42}$ Cfr. Andereggen: La Metafísica de santo Tomás..., p. 213.
} 
En el siguiente texto se ve claramente cómo se enlazan las nociones de participación del ser y de cantidad virtual.

Hay dos cantidades: la dimensional, que se considera según la extensión, y la virtual, que se toma según la intensidad. Pues la virtud de una cosa es su perfección, según aquello del Filósofo (Físicos, VIII): cada cosa es perfecta cuando alcanza su propia virtud. Y así la cantidad virtual de cada forma se considera según el modo de su perfección.

Ambas cantidades se multiplican por muchas especies. Pues bajo la cantidad dimensional se contiene la longitud, la latitud y lo profundo, y el número en potencia. Pero la cantidad virtual en tantas se distingue, cuantas son las naturalezas o formas, el modo de perfección de las cuales hace toda la medida de la cantidad.

Sucede que lo que es finito según una cantidad, sea infinito según otra. Pues puede pensarse que una superficie es finita según la latitud e infinita según la longitud. Es evidente esto también si se toma una cantidad dimensional y otra virtual. Pues si se piensa en un cuerpo blanco infinito, no por eso la blancura será intensivamente infinita, sino sólo extensivamente y per accidens. Pues podría encontrarse algo más blanco.

Pero esto también es evidente si ambas cantidades son virtuales. Pues en una y la misma cosa se puede atender a diversas cantidades virtuales, según las diversas razones de aquellas cosas que del mismo se predican. Como por esto que se dice que algo es ente, se considera en eso la cantidad virtual en cuanto a la perfección del ser; y al llamarla sensible se considera en eso la cantidad virtual a partir de la perfección del sentir; y así siguiendo.

Por lo tanto, en cuanto a la razón del ser, no puede ser infinito sino aquello en lo que se incluye toda la perfección del ser, que puede variar en diversos infinitos modos. Y de este modo, sólo Dios es infinito por esencia, porque su esencia no es limitada a alguna determinada perfección, sino que incluye en sí todo modo de perfección a que se pueda extender la razón de entidad, y por eso Él es infinito por esencia.

Esta infinitud no puede corresponderle a ninguna creatura, pues el ser de toda creatura está limitado a la perfección de su propia especie. 43

En este texto aparecen temas centrales de la metafísica tomista de la participación, en vinculación con el tema de la cantidad virtual. Así como la cantidad dimensional se multiplica según las tres dimensiones y el número, la cantidad virtual se multiplica según las diversas esencias y formas. Claramente aparece aquí la idea de la esencia como modus essendi, como medida del ser, es decir, como determinante de la potentia essendi o virtus essendi. En Dios, su esencia se identifica con el ser y por eso es el ser de modo ilimitado. Por esta razón, sólo Dios es infinito por esencia. Todas las demás perfecciones son participaciones en modos particulares de ser. Hay que resaltar también la idea de infinitud relativa, tomada del De causis. Sólo Dios es infinito absolutamente, pero las creaturas pueden serlo secundum quid, en un aspecto. Esta infinitud es relativa, pues se da en el ámbito de un modo limitado

43 De ver, q. 29, a. 3, co. 
de ser, de una determinada especie o género. Por ejemplo, cada sustancia puramente espiritual (el ángel) agota totalmente su especie pues la posee según todo su poder o cantidad virtual, y no participada en un sujeto. Lo mismo sucedería si se diera el caso hipotético de que existieran el blanco o el calor separados, o incluso cantidades dimensionales infinitas, como una longitud infinita. Sin embargo respecto de la perfectio essendi, estas serían finitas pues no poseerían el ser según toda la virtud del ser.

Este es el motivo por el que santo Tomás, en el texto citado al comienzo de este estudio $^{44}$, distinguía entre la cantidad virtual de la esencia, la del mismo ser y la de la operación. Por eso, el Aquinate recurre a veces a la noción de quantitas virtualis para referirse a la intensidad de perfección propia de una determinada naturaleza, a la participación de la misma perfectio essendi, y a la intensidad con que se posee o funciona una virtud operativa, o con que se posee cualquier otra cualidad.

En el texto citado un par de párrafos atrás aparece una palabra que es muy importante para definir a la cantidad virtual: se trata de la palabra intensidad. Mientras que la cantidad dimensional se caracteriza por ser extensa y tridimensional, de tal manera que algo se dice grande según que posee mayor latitud, longitud y/o profundidad; la cantidad virtual se caracteriza por ser intensa, es decir susceptible de ser poseída con mayor intensidad o remisión. La posesión del ser en toda su intensidad es propia sólo de Dios. Las creaturas poseen el ser con una cantidad virtual limitada, diferenciándose entre sí por la mayor o menor intensidad en que inhiere en ellas el ser. Esta intensidad depende del modo de ser determinado por su esencia. De acuerdo a este modus essendi se dispone ordenadamente la realidad en una jerarquía ontológica cuya parte virtualmente superior (según un arriba virtual, no dimensional) tiene una naturaleza que participa más intensamente del ser. De la misma medida de la naturaleza depende también la virtud operativa de cada cosa, que no es otra cosa que una expansión y completamiento de la perfección inicial del ser sustancial, a través del ser accidental. 45

\section{Realismo de la cantidad virtual: contacto y ubicación virtual}

Si bien la noción de cantidad virtual es presentada por el Aquinate a partir de la de cantidad dimensional, haríamos mal en pensarla como un mero modo de hablar. La noción de quantitas virtualis nos abre la puerta a la riqueza de la concepción que santo Tomás tuvo del mundo espiritual. En el parágrafo anterior decíamos que

44 S. Th., I, q.42, a.1, ad 1.

45 No es nuestra intención dilucidar en esta sede si cuando santo Tomás habla del esse del accidente se está refiriendo al esse in actu o al esse ut actus. Para un repaso muy documentado de este tema, cfr. Wippel: The Metaphysical Thought..., pp. 253-265. 
según la cantidad virtual hay como un arriba-abajo virtual. No son meros conceptos, sino una casi ubicación real en una parte del universo que escapa a la vista de los sentidos, pero que es más real, por ser más intensa su cantidad de ser. En los siguientes parágrafos señalaremos varios ejemplos, algunos de los cuales demuestran un modo muy realista de concebir la cantidad virtual.

En varios textos, santo Tomás se refiere a un toque, tacto (tactus) o contacto virtual (contactus virtualis). No es, sin lugar a dudas, el contacto entre dos cuerpos dotados de cantidad dimensional, sino de algo distinto y sin embargo real. Así como los cuerpos por estar dotados de cantidad dimensional pueden entrar en contacto físico unos con otros, también puede haber un contacto de tipo incorpóreo, un contacto virtual. Este toque virtual puede aplicarse a muchos casos distintos, desde el contacto que las cosas tienen con los afectos, por mediación de la cognición (ver cita siguiente), hasta el contacto entre las realidades espirituales, o de éstas con las cosas materiales.

El contacto [tactus] es de dos tipos: corporal, como dos cuerpos se tocan; y virtual, como se dice que lo que causa tristeza toca al que está triste. Según el primer contacto, Dios, dado que es incorpóreo, ni toca, ni es tocado. Pero según el contacto virtual, toca moviendo a las creaturas, pero no es tocado, porque ninguna virtud natural de la creatura puede llegar hasta Él. Y así entiende Dionisio que no hay tacto de Dios, de tal manera que se lo toque. 46

Decimos con frecuencia que un determinado suceso nos "toca" afectivamente. Se trata de un toque virtual. De modo semejante puede decirse que Dios toca a las creaturas al moverlas. Independientemente de las consideraciones propias de la teología mística que este pasaje pueda sugerir (como los "toques sustanciales" de algunos místicos), que exceden las posibilidades y objetivos de un estudio como el presente, aquí aparece la sugerente expresión "contacto virtual", cuyo parentesco con la "cantidad virtual" es fácil entrever. 47 Como se puede comprobar si se leen los textos completos en que suele aparecer esta expresión, en los mismos se está tratando de otra consecuencia "virtual" de la magnitud espiritual, que es la localización o ubicación virtual. En el contexto del tratamiento de este tema aparecen interesantísimas consideraciones del Aquinate, como en el siguiente texto:

Al ángel le corresponde estar en un lugar, pero se dice equívocamente que el ángel está en un lugar y que lo está un cuerpo. Pues el cuerpo está en un lugar porque se le aplica un lugar según el contacto de la cantidad dimensional. La cual no se da en los ángeles. Pero en ellos sí se da la cantidad virtual. Entonces, por la aplicación de la virtud angélica a un lugar de alguna manera, se dice que el ángel está en un lugar corpóreo. Y según

46 S. Th. I, q. 105 a. 2 ad 1. 
esto es evidente que no se debe decir que el ángel esté conmensurado por el lugar o que se ubique en un continuo, pues esto es propio del cuerpo localizado en cuanto tiene cantidad dimensional. Por lo mismo, no se sigue de esto que esté contenido por el lugar. Pues la sustancia incorpórea que con su virtud contacta con la cosa corpórea la contiene y no está contenido por ella; pues el alma está en el cuerpo como contenedora y no como contenida. Y de modo semejante se dice que el ángel está en un lugar corpóreo, no como contenido, sino de algún modo como contenedor. 48

En este texto se nos habla, decíamos, de una especie de $u b i$ virtual, concomitante a la quantitas virtualis. Así como de la cantidad dimensional se sigue la localización de un cuerpo que se halla en relación de contenido respecto de otros cuerpos que lo rodean y contienen, de modo semejante de la cantidad virtual se sigue una relación de contenido y continente que podemos llamar "localización virtual".49 De esta manera se puede hablar de un cierto $u b i$ en las cosas espirituales, aunque de naturaleza distinta que el de las materiales. En el texto que comentamos, se habla en particular de la localización de las sustancias espirituales en cuerpos sobre los que ejercen su poder. El Aquinate dice muchas veces que se puede decir que las sustancias espirituales están en los cuerpos sobre los que actúan. Este modo de estar en un lugar no es sin embargo el del ubi predicamento, sino que supone un contacto de virtud, no físico. Por este contacto virtual la creatura espiritual se dice estar en aquello sobre lo que actúa, pero de otro modo. Y más se podría decir que ella es el continente de aquello sobre lo que actúa, que al revés. Así se dice que el alma está en el cuerpo, pero no como contenida por el cuerpo sino más como continente, por referirse a éste como el acto a la potencia, de modo semejante a como el lugar se comporta respecto de aquello que localiza también como acto. 50 De modo semejante, la sustancia espiritual que actúa sobre otra realidad, más se dice que contiene a esa realidad, que ser ella misma contenida por aquella.

Atiéndase bien a este dato: si bien aquí se dice que la creatura espiritual está en un lugar, sería mejor decir que ella contiene en sí, como un lugar virtual, a la realidad sobre la que ejerce su causalidad. En el caso del alma, se trata de la causalidad formal; en el del ángel, de la causalidad eficiente. Es importante también hacer una observación más. En los ejemplos puestos por el Aquinate, el del alma y el del

\footnotetext{
47 Sobre el contacto virtual, cfr. también $S$. Th. I, q. 53 a. 2 ad 1; S. Th., III, q. 56 a. 1 ad 3; De subst. separatis, cap. 19 co; De Ver., q. 8, a. 14, ad 2.

48 S. Th., I, q. 55 , a. 1 , co.

49 Si bien santo Tomás afirma que aquí se habla de lugar equívocamente, sabemos bien que a veces el Aquinate llama equívoco a lo análogo; cfr. McInnerny, R. M.: Aquinas and Analogy, Washington D.C., The Catholic University of America Press, 1996.

50 Santo Tomás dice muchas veces que el alma se relaciona con el cuerpo como el continente con lo contenido, de tal manera que es mejor decir que el cuerpo está en el alma, que no que el alma está en el cuerpo. Por ejemplo, cfr. S. Th., I, q. 8, a.1, ad 2; S. Th., I, q. 76, a. 3, co.; In I De anima, 1. 14, n. 8.
} 
ángel, estamos en ambos casos ante una realidad espiritual que contacta virtualmente con una realidad corporal. En esta situación, parece que estamos más cerca de la noción inicial de cantidad, la predicamental. Pero también se da el caso del contacto virtual entre dos realidades espirituales (ángel con ángel, o ángel con alma humana, o Dios con las creaturas espirituales). Como veremos, también en este caso se puede hablar de una cierta ubicación virtual. Pero antes de pasar a esto, permítasenos analizar otro texto que nos ayuda a profundizar en estas ideas:

Se puede considerar de qué manera esté el ángel en un lugar corpóreo a partir del modo en que el cuerpo está en un lugar. El cuerpo está en el lugar por el contacto local. Pues el contacto del cuerpo es por la cantidad dimensional, que en el ángel no se encuentra, por ser incorpóreo; pero en su lugar en éste se da la cantidad virtual. Por lo tanto, así como el cuerpo está en el lugar por el contacto de la cantidad dimensional, el ángel está en el lugar por el contacto de virtud. Si alguien quiere llamar al contacto de virtud "operación", porque operar es el efecto propio de la virtud, se puede decir que el ángel está en el lugar por la operación. Pero de tal modo que por operación no se entienda la sola moción, sino una cierta unión por la que por su virtud se une al cuerpo, presidiendo o conteniendo, o de algún otro modo. ${ }^{51}$

Santo Tomás pone muy en claro que la operación de un ente espiritual sobre otro ente da lugar a una verdadera unión o contacto, que aquí es algo así como un contener a la realidad sobre la que actúa. En esta línea, y para comprender el alcance de la concepción tomasiana de la ubicación virtual, es muy interesante el siguiente texto, que expresa un aspecto central de su contemplación metafísica del universo, y que se refiere al contacto entre realidades espirituales:

Puesto que el ángel tiene naturalmente una luz intelectual más perfecta que el hombre, por ambas partes puede ser causa de ciencia para el hombre; aunque de inferior modo que Dios, y superior que el hombre. Pues de parte de la luz, aunque no pueda infundir la luz intelectual, como lo hace Dios, puede reforzar la luz infusa para una más perfecta visión. Pues cuando todo lo que es imperfecto en algún género es continuado por lo más perfecto en ese género, su virtud es más reforzada. Como también vemos en los cuerpos que el cuerpo ubicado es reforzado por el cuerpo que la ubica, que se compara a él como el acto a la potencia, como se dice en el IV de los Físicos. ${ }^{52}$

El texto citado trata sobre el modo en que los ángeles causarían la ciencia en los hombres. Esto podrían hacerlo de dos maneras: una objetiva y otra subjetiva. La primera consistiría en proponer un objeto para su contemplación. La segunda, en reforzar el intelecto para hacerlo más potente. La primera manera de causar la ciencia es exterior. La segunda es interior, aunque se diferencia del modo en que Dios mismo

51 Quodl.1, q. 3, a. 1, co.

52 De Ver, q. 11, a. 3, co. 
ilumina. En efecto, este último infunde interiormente la luz intelectiva, ya sea naturalmente, pues Dios en cuanto es Creador es causa de las facultades intelectivas del hombre 53 , ya sea sobrenaturalmente, a través de todas las luces infundidas con el hábito de la gracia (la fe, los dones de consejo, ciencia, inteligencia y sabiduría, las iluminaciones carismáticas, etc.). Todos estos modos de iluminar tan interiormente serían propios sólo de la causa primera del ser, es decir de Dios Creador. El ángel lo haría de otro modo. Así como las cosas materiales, es decir, dotadas de cantidad dimensional, al estar ubicadas o localizadas son como reforzadas por el cuerpo que las contiene, localizándolas, relacionándose con ellas como el acto respecto de la potencia -pues el ubi es una categoría que depende de que un cuerpo esté circunscripto por otros- algo semejante sucede con los entes espirituales. No sólo hay una escala de perfección, y también una cierta continuidad (continuatio) $)^{54}$ por la que los extremos de actualidad se tocan, pues lo superior de lo inferior y lo inferior de lo superior están en contacto virtual; sino que lo espiritualmente superior es como si contuviera en sí a lo inferior, no sólo en el sentido de que al poseer más intensamente el ser, de algún modo tiene de un modo más perfecto lo que el inferior posee de modo imperfecto, sino incluso porque a eso mismo inferior lo puede "abrazar", confortándolo. 55

Estas afirmaciones nos confirman el realismo con el que el Aquinate concibe la cantidad espiritual. Cuando se habla de magnitud, contacto, ubicación, etc., de las realidades espirituales, aunque para nuestra luz intelectual participada parezca tratarse de una proyección borrosa de nuestra experiencia sensible, en realidad se está hablando de una realidad más rica, más potente, más consistente, con mayor virtus essendi, de la que apenas percibimos su sombra.

\footnotetext{
53 Por ser la luz intelectiva natural infundida por Dios en la creación del alma, la acción del intelecto agente, por ser natural, aun siendo el acto de una potencia propia del supuesto humano, de algún modo se puede atribuir más a Dios que al hombre, y por eso se puede decir que Él ilumina a todo hombre, como decía san Agustín.

54 Por ejemplo, cfr. De veritate, q. 9, a. 1, co. Sin embargo, hay que notar que la expresión continuatio es utilizada en general por santo Tomás en el contexto polémico de la discusión con la posición de los árabes sobre el intelecto separado por cuya continuación con nuestro intelecto pasivo nosotros entenderíamos, posición que el Aquinate rechaza.

55 La fuente de santo Tomás en estos temas es, por supuesto, el Pseudo-Dionisio. No se puede olvidar, también, la influencia de san Alberto Magno, que comentó toda la obra de Dionisio. A continuación, citamos un interesante pasaje de su comentario a la Teología Mística del Areopagita: "Ad alium dicendum, quod sicut est continuatio sensibilium luminum, ita est continuatio intelligibilium. Cum igitur divina non possint accipi per conexiones probabiles vel necessarias ex principiis primis, in quae sola potest lumen intellectus agentis sicut in propria sua instrumenta, oportet, quod ad huiusmodi cognoscenda adveniat sibi lumen intellectus angelici, quod multiplicat in animas nostras species quasdam in quibus videntur divina, $[\ldots]$ et multo magis roboratur anima videnda divina, secundum quod ipsum divinum lumen descendit in ipsam; et forte coniungitur uterque modus" (Alberti Magni, Super Dionysii Mysticam Theologiam, edidit Paulus Simon, Monasterii Westfalorum in Aedibus Aschendorff, 1978, p. 464a-b).
} 


\section{Igualdad virtual y crecimiento virtual}

De modo semejante a como la cantidad virtual da lugar a poder hablar de una grandeza y pequeñez, arriba y abajo, contacto y separación, y a una localización espirituales, también da lugar a otras consecuencias como a poder hablar de una igualdad de virtud, a un movimiento y a un crecimiento virtuales, etc. Santo Tomás lo hace con frecuencia.

Comencemos por el tema de la igualdad. Ya hemos dicho al inicio de este estudio que probablemente el tema de la cantidad virtual haya surgido a partir del tema del estudio de la igualdad de las Personas divinas. Sobre la igualdad virtual, leemos:

La igualdad es una cierta relación fundada sobre la unidad de la cantidad, y en lo divino fundada sobre la unidad de la esencia, según que es significada por el nombre de cantidad virtual, como cuando se dice magnitud, o eternidad, o potencia. ${ }^{56}$

La verdad es una relación de igualdad (adaequatio). 57 Esa igualdad no se da según la cantidad dimensional, sino según la cantidad virtual.

Per se, no se compara el inteligible al intelecto según la cantidad dimensional, puesto que el intelecto es una fuerza que no usa órgano corporal; sino que per se se le compara sólo según la cantidad virtual. 58

Ahora bien, puede haber objetos cognoscibles en sí pero que superen por su cantidad virtual a la de nuestra potencia cognoscitiva, por lo que no se puede lograr la total adecuación propia del conocimiento perfecto:

Se dice que lo cognoscible excede a la potencia cognoscitiva según esa cantidad de acuerdo a la cual es cognoscible por la misma. Lo sensible se conoce por un lado según la cantidad dimensional, porque el sentido al conocer utiliza un órgano corporal, y por esta razón conoce todos los sensibles que se reducen a la cantidad dimensional [es decir los sensibles comunes]. Por otro, según la cantidad virtual, como es evidente en los sensibles propios, que son cualidades. Y por eso también la comprensión del sentido es impedida tanto por el exceso de la cantidad dimensional, como está incapacitada para abarcar la totalidad de la tierra; y por el exceso de cantidad virtual, como está incapacitada para captar perfectamente la claridad del sol. Porque no es tanta la fuerza [virtus] del ojo para conocer toda la claridad del sol que es cognoscible. Pero lo inteligible no es conocido por el intelecto bajo la razón de cantidad dimensional, a no ser per acci-

\footnotetext{
56 In I Sent., d. 31 q. 1 a. 1 co.

57 Cfr. Contat, A.: La relation de vérité selon saint Thomas d'Aquin, Città del Vaticano, Libreria Editrice Vaticana, 1996.

58 De ver, q. 8 a. 2 co.
} 
dens, en cuanto recibe del sentido; de lo que se sigue que entienda con el continuo; y según esto el intelecto se ve incapacitado para la comprensión de lo inteligible por un exceso de cantidad; como está impedido para la comprensión de líneas o números infinitos. Pero hablando per se, lo inteligible se compara al intelecto según la razón de cantidad virtual, porque el objeto propio del intelecto es el qué; y por eso en aquello que está separado del sentido, la comprensión del intelecto no se impide sino por un exceso de cantidad virtual. Y esto es cuando el inteligible es más cognoscible que lo que el intelecto puede o conoce. Como aquel que sabe la conclusión "el triángulo tiene tres..." por una razón probable, o porque así se dice comúnmente, no la comprende. No porque vea una parte y no vea otra parte, sino porque el modo por el que conoce es deficiente respecto del modo por el que es cognoscible por demostración. 59

También se refiere santo Tomás a un aumento o crecimiento virtual, como en el texto siguiente:

Se debe decir que la caridad aumenta esencialmente. Hay que saber que aumentar no es otra cosa que adquirir una mayor cantidad. Por lo que así como uno está dispuesto respecto de la cantidad, así se refiere al aumento. Pero la cantidad se dice de dos maneras: cantidad virtual y cantidad dimensional.

La cantidad virtual no es cantidad por su género, pues no se divide por la división de su esencia; sino que su magnitud se toma de algo divisible exterior, o multiplicable, que es el objeto o acto de virtud ${ }^{60}$. Pero por su género es, o una forma accidental en el género de la cualidad, o una forma sustancial, que sin embargo no es mayor o menor. Por lo tanto, el aumento según la cantidad de virtud no pertenece a la especie de movimiento que se llama aumento, sino más a la alteración. De este modo aumenta la caridad, y también las demás cualidades. 61

Las realidades cualitativas son cuantas con cantidad virtual. Esto vale tanto para las cualidades que están en la materia, como para las cualidades espirituales, cuyo crecimiento pertenece al movimiento de alteración. Sin embargo, mientras que estas últimas de ningún modo se puede decir que sean cuantas con cantidad dimensional (ni per se, ni per accidens), las primeras, se puede decir que tienen cantidad dimensional per accidens, en la medida en que su sujeto es un cuerpo determinado por la cantidad dimensional. 62

59 In IV Sent., d. 49 q. 2 a. 3 co.

60 Esta afirmación vale sólo para la cantidad virtual de las virtudes operativas, no de la esencia ni del ser. Pero se ve aquí una posible vía para reconducir la cantidad dimensional y la cantidad virtual a una unidad analógica por su referencia a algo uno. Entre los varios textos interesantes en que se habla de que la cantidad de virtud se mide por los objetos, resaltan los siguientes: In I Sent., dist. 17, q. 2, a. 1, ad 2; In I Sent., dist. 3, q. 5, a. 1, ex; In I Sent., Dist. 17, q. 2, a. 1, ad 2; In I Sent., dist. 39, a. 2, obj. 3; In I Sent., Dist. 44, q. 1, a. 4, obj. 5 ; Summa Theologiae, I-II, q. 66, a. 5, co; De Virtutibus, q. 1, a. 11 , ad 10.

61 In I Sent., dist.17, q. 2, a. 1, co.

62 In I Sent., dist. 17, q. 2, a. 1, ad 1. 
Si bien se llama propiamente aumento al cambio de magnitud cuantitativa de un cuerpo, es decir según la cantidad dimensional, sin embargo, en la medida en que según la cantidad virtual existe un más y un menos, se puede hablar de un aumento o crecimiento virtual de las formas. ¿En qué consiste este aumento? Se trata de una mayor intensidad de la virtud63. La medida de la cantidad virtual se toma sobre todo de la intensidad y modo con que inhiere una forma en el sujeto ${ }^{64}$, más que de su objeto.

En el siguiente texto, el crecimiento se relaciona claramente con la idea de grandeza virtual. Aumentar es moverse hacia la cantidad perfecta, en este caso cantidad de perfección, es decir, de bondad:

Por lo que en las formas decimos que algo es grande, porque es perfecto. Y porque el bien tiene razón de perfecto, por eso "en las cosas que no son grandes por su mole, es lo mismo se mayor que mejor", como dice san Agustín en el 1. VI Sobre la Trinidad. Pero la perfección de la forma se puede considerar de dos modos. Primero, según la forma misma. Segundo, según que el sujeto participa de la forma. 65

Una cosa es participar de una forma, más o menos perfecta, y otra, participar más o menos intensamente de una perfección. En el caso de la virtud de la caridad, por ejemplo, no se puede crecer en cuanto al objeto, porque el objeto de la caridad es Dios y no se puede tener un objeto superior a éste, sino en la intensidad con que la virtud actúa o inhiere en el sujeto. Esa intensidad puede ir en aumento hasta alcanzar la medida perfecta para este determinado ente, y eso es crecer en la caridad.

Como el cuerpo que se mueve hacia la cantidad perfecta se dice que aumenta, también la cantidad perfecta misma se llama grande respecto de la imperfecta ${ }^{66}$. De tal modo que lo que se mueve desde la cualidad imperfecta hacia la perfecta se dice que aumenta según la cualidad. Y la cualidad perfecta misma se llama grande respecto de la imperfecta. Y como la perfección de cada cosa es su bondad, san Agustín dice que "en aquellas cosas que no son grandes por su mole, es lo mismo ser mayor que ser mejor". Pero moverse de la forma imperfecta a la perfecta no es sino que el sujeto sea más llevado al acto: pues la forma es acto. Por eso, que el sujeto reciba más la forma, nada es sino que éste sea llevado más al acto de aquella forma ${ }^{67}$.

63 S. Th., II-II, q. 24, a. 4, ad 1.

64 S. Th., I, q. 65 , a. 3 , ad 3.

65 S. Th., I-II, q. 52 a. 1 co.

66 Como vemos, entre el punto de partida y el punto de llegada de este movimiento hay una cierta "distancia" virtual. En santo Tomás la palabra distancia se usa con frecuencia en este sentido de distancia de perfección. Para poner sólo uno de los múltiples ejemplos que se podrían poner, cfr. In I Sent., dist. 31, a. 2, ad 1. Santo Tomás habla también de una especie de "dilatación" virtual; cfr. Summa Theologiae, I-II, q. 33, a. 1, co.

67 De virtutibus, q. 1 a. 11 co. 
Este texto nos devuelve a la lógica de aquél que citamos al comienzo: de la cantidad de la esencia dependen tanto la cantidad del ser como del operar. Pero a su vez se debe recordar que la sustancia creada llega a su plenitud a través de la operación y que, según el Aquinate, se asemeja más a Dios por su operación que por el sólo hecho de ser. ${ }^{68}$ Esto es así porque por la operación la creatura participa más perfectamente de aquella perfección que en el Esse intensivo69 de Dios se encuentra unidamente y de modo ilimitado. Esto es importante recalcarlo porque una concepción exclusivamente descendente del ser participado, según la cual toda forma o esencia particular es "disgregación" del ser o incluso es "caída" del ser, lleva por su misma lógica a considerar que las formas accidentales son ulteriores caídas del ser, por debajo de la caída del ser sustancial en la forma sustancial, como podría considerárselo tanto desde el emanatismo neoplatónico, como desde la concepción heideggeriana del Dasein como estructuralmente caído. 70

\section{La división de la cantidad virtual: todo y partes; multiplicidad trascendental; unidad y medida}

Así como la cantidad dimensional se puede dividir, tanto potencialmente en el interior de la cantidad continua (todo y partes), como deshaciendo ésta dando lugar a varios continuos distintos, es decir, a la cantidad discreta (unidad y multiplicidad), también se puede dividir la cantidad virtual. Respecto de lo primero, ya hemos mencionado cómo la imagen de la parte está implicada en la noción misma de partici-

68 Cfr. S. Th., I, q. 93, a. 7.

69 O'Rourke (Pseudo-Dionysius..., p. 155) conecta la idea de virtus essendi con la noción fabriana de esse intensivo. Sin embargo, el mismo autor, considera que Fabro no aprovechó suficientemente el tema de la cantidad virtual en su conexión con la virtud y la intensidad (p. 166): "Cornelio Fabro does not seem to have explained the wide wealth of text by Aquinas on virtual quantity and the connection between virtus and intensity. Perhaps this is not all too surprising, since it is only en passant that Aquinas himself makes explicit the identity between 'virtual' and 'intensive' quantity".

70 Cfr. Heidegger, M.: El ser y el tiempo, Madrid, Planeta-De Agostini, 1993, p. 195 (§38): "El 'ser ahí', es inmediatamente siempre ya 'caído' 'de' sí mismo en cuanto 'poder ser sí mismo' propiamente y 'caído' 'en' el 'mundo'." La desorientación de estas posiciones proviene de no comprender el carácter relativo del no-ser de las creaturas. Santo Tomás afirma a veces que una especie determinada (o un individuo) contiene en sí la negación de las otras, que por ello le son opuestas. Con esto se está queriendo decir que en cuanto participación limitada del actus essendi, cada especie e individuo incluye en sí un no-ser relativo: una especie no es la otra; un individuo no es el otro. Sin embargo, la afirmación del idealismo de que omnis determinatio est negatio, no toma la negación y el no-ser en este sentido relativo, sino confundiendo la negatio con la privatio, y convirtiendo esa oposición en mal ontológico. De ese modo, el ente particular, al tener un esse limitado, implicaría una "caída" ontológica, y su carencia de ser sería una verdadera privación que la haría, en cuanto particular, mala y, en el caso de las personas, estructuralmente culpables (como sucede desde Hegel hasta Kierkegaard, contracara del idealismo, y su secularización heideggeriana). Cfr. González, A. L.: Ser y Participación, Pamplona: EUNSA, 2001, p.123-124. 
pación. Santo Tomás con frecuencia también dice que además de partes cuantitativas, existen otros tipos de partes, especialmente las partes potenciales, que son justamente partes de virtud: El todo virtual tiene plenamente lo que cada una de las partes virtuales tiene limitadamente ${ }^{71}$. Razones de brevedad no nos permiten desarrollar ampliamente este tema en esta sede. ${ }^{72}$ Sin embargo, no queremos cerrar este estudio sin hacer referencia a otro aspecto del tema, que aquí no podemos más que señalar como de pasada. La idea de quantitas virtualis o magnitudo spiritualis está desarrollada principalmente sobre la semejanza de la cantidad continua, que puede ser más o menos grande. Pero un desarrollo ulterior del tema podría abordarla desde la semejanza con la cantidad discreta. Desde este punto de vista, se podría tratar el tema, central en la metafísica desde la antigüedad, de lo uno y lo múltiple.

Con frecuencia, el Aquinate distingue la unidad, pluralidad y número de las cosas materiales en cuanto dotadas de cantidad dimensional, de la unidad y multiplicidad trascendentales. Unidad y multiplicidad "sunt de transcendentibus". Mientras que la multiplicidad en las cosas dimensionales proviene de la división de la cantidad continua, la pluralidad virtual procede de la multiplicación de las formas. En las realidades compuestas de materia y forma, una forma sustancial de la misma especie puede ser participada por varios sujetos. En las realidades puramente espirituales, cada ente poseería en modo completo y perfecto (infinito, ilimitado en su orden), su propia forma.

En los ángeles no se da el número que es cantidad discreta, causado por la división del continuo, sino causado por la distinción de las formas, en cuanto la multitud es un trascendental, como antes se dijo ${ }^{73}$.

El número causado por la división del continuo es una especie de la cantidad, y se da sólo en las sustancias materiales. Pero en las sustancias inmateriales se da la multitud que forma parte de los trascendentales, según que uno y muchos dividen el ente. Esta multitud es consiguiente a la distinción formal74.

Hay una doble división: una formal, que se da por los opuestos, y otra según la cantidad. La primera división causa la multiplicidad que es trascendental, según que el ente se divide por uno y muchos. Pero la división de la cantidad continua causa el número que es especie de la cantidad, en cuanto tiene razón de medida. Este número es multiplicable al infinito, como también la magnitud es divisible al infinito. Pero la multiplicidad que sigue a la división formal de las cosas, no se multiplica al infinito. Pues hay determinadas especies de cosas, como también es determinada la cantidad del universo ${ }^{75}$.

\footnotetext{
71 Por ejemplo, cfr. Q. disp. de anima, q. 10, co.

72 Como ejemplos de textos en que se relaciona el tema del todo y la parte con la cantidad virtual, sirvan los siguientes: In I Sent., dist. 19, q. 4, a. 1, obj. 1: In I Sent., dist. 19, q. 4, a. 1, ad 1 ; In I Sent., dist. 3, q. 5, a. 1, ex; De ver., q. 15 a. 2 ad 2.

73 S. Th., I, q. 50, a. 3, ad 1.

74 De Spirit Creaturis, a. 8, ad 15.

75 In III Phys., 1. 12, n. 5.
} 
Las formas dividen a los entes según una multiplicidad no material, de modo parecido a como hay también una magnitudo spiritualis, a semejanza de la magnitudo corporalis. La determinata quantitas universi nos reconduce a la noción de esse commune, que tiene, en cuanto realidad creada, una determinada cantidad de virtus essendi. Pero también hay una cantidad determinada de especies e individuos.

Si pasamos al tema del número, es significativa la afirmación aristotélica, citada con frecuencia por santo Tomás, de que las especies son como los números (sunt sicut numeri): así como el agregado de una unidad varía el número realmente cuantitativo, el agregado de una diferencia hace que se modifique la especie; casi como si las diferencias aportaran un monto de cantidad virtual propio. ${ }^{76}$ Así como el uno es la medida de la cantidad dimensional, aquello que es perfecto en un determinado orden de perfección es causa y medida de todo lo que participa de ese orden perfectivo. Este principio, que aparece formulado de múltiples maneras en la obra de santo Tomás, es el que preside la cuarta vía para demostrar la existencia de Dios77, y tiene estrecha vinculación con la cantidad virtual:

En cualquier género lo que es más simple y perfecto es medida de los demás, como la blancura en los colores, y en los movimientos el movimiento diurno. Porque cada cosa es tanto más perfecta cuanto más alcanza al principio de su género. Por lo cual se evidencia que la perfección de cada cosa, según la cual se considera su mensuración, depende del primer principio. De modo semejante, su cantidad. Y esto es lo que dice Agustín, en el 1. VIII Sobre la Trinidad, que "en las cosas que no son grandes por su mole, es lo mismo ser mejor que mayor".78

Dios es el primero en el orden del ser, pues en él se contiene ilimitadamente toda la virtus essendi. Como toda perfección es tal en cuanto tiene de ser, en Dios se precontienen todas las perfecciones de todas las cosas. Por eso Dios es medida de todas las cosas, una medida trascendente que supera todo género, pues su causalidad trasciende todos los géneros:

Se habla propiamente de "medida" en las cantidades. Pues se llama medida aquello por lo que se conoce la cantidad de una cosa, y esto es lo mínimo en el género de la cantidad, como en los números, que se miden por la unidad, o lo mínimo según nuestra posición, como en los continuos, en los que no hay un mínimo absoluto. Por eso usamos el palmo como mínimo para medir una tela, o un estadio para medir una calle. Desde ahí se trasladó el nombre de medida a todos los géneros, de tal manera que aquello que es primero y más simple en cada género se llame medida de todas las cosas que están en

76 Cfr. Contra Gentes, 1. 4, c. 41, n. 3.

77 S. Th., I, q. 2, a. 3, co.

78 De virtutibus, q. 5 a. 3 co. 
ese género 79 . Porque se sabe que cada uno tiene más o menos respecto de la verdad del género, según que se acerca más a este o se aleja de él, como lo blanco en el género de los colores. Así también, en el género de la sustancia, aquello que tiene el ser más perfecto y simple se llama medida de todas las sustancias, como Dios. Por lo que no debe estar en el género de la sustancia como contenido, sino sólo como principio, teniendo en sí toda la perfección del género, como la unidad en los números, pero de otro modo; porque por la unidad no son medidos sino sólo los números. Pero Dios es medida, no sólo de las perfecciones sustanciales, sino de todas las que están en todos los géneros, como de la sabiduría, la virtud, etc. Por eso, aunque la unidad se contenga en un género determinado como principio, Dios no. 80

Dios es medida de todas las perfecciones, tanto del ser sustancial como de cualquiera de las otras perfecciones que se colocan en todos los géneros. Por ser una causa que trasciende todo género, no se coloca en ninguno de ellos, ni siquiera como principio. Esto nos permite, para cerrar este estudio, señalar un aspecto que complementa y matiza las afirmaciones vertidas a los largo de este trabajo. Si bien el esse como actus essendi es la perfección de las perfecciones que contiene de alguna manera, intensivamente, toda otra perfección, que no es tal sino en tanto que es, y por lo tanto en dependencia del acto de ser, sin embargo, para nuestro modo limitado de conocer, no basta la denominación de Dios sólo a partir del ser. Entre otras cosas, porque el esse que es acto de los entes que son proporcionados a nuestro modo de conocer es un esse inherente, no subsistente. ${ }^{81}$ La perfecta infinitud de la perfección divina subsistente es algo a lo que nos vamos aproximando a partir de la atribución a Él de todas las perfecciones creadas, removiendo lo que tienen de imperfección en nuestro modo de conocer y denominar, y afirmando la absoluta trascendencia de la perfección sin ningún límite de Dios.

\section{Conclusión}

Consideramos que con lo dicho en este artículo hemos puesto de manifiesto la importancia y virtualidades de la noción de quantitas virtualis como principio explicativo de capital importancia en la metafísica de santo Tomás. Sintetizando, podemos decir lo siguiente:

\footnotetext{
79 Esta idea de lo "mínimo" como medida de un género, que se traduce en el ámbito formal como lo más simple, da lugar a la afirmación de Dionisio de que Dios puede ser llamado tanto "grande" como "pequeño", esto último, entre otras cosas, en cuanto es medida de todas las cosas; cfr. In De Div. Nom., c. $9,1.1$.

80 In I Sent., dist. 8, q. 4, a. 2, ad 3.

${ }^{81}$ In Boeth. De Hebd., 1. 2. Cfr. Contra Gentes, L. I, cap. 30.
} 
1. Así como hay una cantidad dimensional, la cantidad predicamental, hay una cantidad de las formas que por semejanza se denomina cantidad virtual.

2. Esta cantidad virtual consiste en la intensidad con que se posee una determinada perfección formal: sea el mismo ser, sea una forma sustancial, sea una forma accidental. Por darse en más de un género, esta cantidad es trascendental.

3. La cantidad virtual se conecta con la noción de participación, en la medida en que esta misma supone el tener particularmente, algo que a otro corresponde ilimitadamente.

4. Algo es más grande con cantidad virtual en cuanto posee más perfectamente un determinado acto o forma.

5. De la cantidad virtual se siguen varias propiedades y situaciones que son muy reales para el mundo espiritual, si bien nosotros las captamos como desde lejos y en su sombra. Se puede hablar así de igualdad virtual, contacto virtual, localización virtual, crecimiento virtual, etc.

6. La noción de cantidad virtual se conecta con la de virtus, porque se trata de la cantidad de perfección de la que se participa. En este sentido se debe destacar especialmente la noción de virtus essendi.

7. Al ser Dios el ser según toda la virtud del ser, se puede decir que Él que es el Ser según toda su virtud o intensidad, es decir, según toda su cantidad virtual. Por eso, es medida de todas las cosas, si bien se trata de una medida que trasciende todos los géneros porque su influjo causal se extiende a todos ellos y porque su cantidad de perfección trasciende toda participación posible.

\section{Referencias bibliográficas}

El texto latino de santo Tomás está tomado del sitio de Internet Corpus Thomisticum, dirigido por Enrique Alarcón: <http://www.corpusthomisticum. org/iopera.html> [28/11/2011].

Agustín, S.: Obras completas. vol. V: Escritos Apologéticos (2º, Madrid, BAC, 1985.

Alberti Magni: Super Dionysii Mysticam Theologiam, edidit Paulus Simon, Monasterii Westfalorum in Aedibus Aschendorff, 1978.

ANDEREgGen. I.E.M.: La Metafísica de santo Tomás en la Exposición sobre el De Divinis Nominibus de Dionisio Areopagita, Buenos Aires, EDUCA, 1989.

Aristóteles: Metafisica. Edición Trilingüe, Madrid, Gredos, 1998.

Cardona, C.: La metafísica del bien común. Madrid, Rialp, 1966.

CONTAT, A.: "Le figure della differenza ontologica nel tomismo del Novecento", en Villagrasa, J. (Ed.): Creazione e actus essendi. Originalità e interpretazioni della Metafisica di Tommaso d'Aquino, Roma, Ateneo Pontificio Regina Apostolorum, 2008. 
CONTAT, A.: La relation de vérité selon saint Thomas d'Aquin, Città del Vaticano, Libreria Editrice Vaticana, 1996.

Dewan, L.: Étienne Gilson y el Actus essendi, en Stella Matutina, 1, 2011, p. 73107.

Dewan, L.: Form and Being. Studies in Thomistic Methapysics, Washington D.C., The Catholic University of America, 2006.

EChAVARRíA, M. F.: Virtud y ser según Tomás de Aquino, en Espíritu, 138, 2009, pp. 9-36.

ElDERs, L.: Conversaciones filosóficas con santo Tomás de Aquino, San Rafael (Mendoza, Argentina), Ediciones del Verbo Encarnado, 2009.

FABRo, C.: La nozione metafisica di partecipazione, Segni, EDIVI, 2005.

FABro, C.: Participación y causalidad según Tomás de Aquino, Pamplona: EUNSA, 2008.

GeIGER, L. B.: La participation dans la philosophie de saint Thomas d'Aquin, Paris, Bibliothèque Thomiste, 1942.

Gilson, E.: "Virtus essendi", en Mediaeval Studies, 26, 1964, pp. 1-11.

GonZÁlez, A. L.: Ser y Participación, Pamplona: EUNSA, 2001.

HeIDEgGer, M.: El ser y el tiempo, Madrid, Planeta-De Agostini, 1993.

MCInnerny, R. M.: Aquinas and Analogy, Washington D.C., The Catholic University of America Press, 1996.

O'Rourke, F.: Pseudo-Dionysius and the Metaphysics of Aquinas, Notre DameIndiana, University of Notre Dame Press, 2005.

O'Rourke, F.: "Virtus Essendi : Intensive Being in Pseudo-Dionysius and Aquinas". En Dionysius, 15, 1991, 31-80.

Ramírez, J.M.: De ordine, Salamanca, San Esteban, 1963.

Ramírez, J. M.: Opera Omnia. Tomus II: De analogia, Madrid, CSIC., 1972.

Wippel, J. F.: The Metaphysical Thought of Thomas Aquinas. From Finite Being to Uncreted Being. Washington, D.C., The Catholic University of America Press, 2000 .

Martín F. Echavarría

Universitat Abat Oliba CEU (Barcelona)

echavarria@uao.es 